\title{
Kitasato Symposium 2010: New Prospects for Cytokines
}

\author{
Gerd R Burmester, Peter E Lipsky and Thomas Dörner*, for the Kitasato Meeting Faculty
}

\begin{abstract}
The Second Kitasato Symposium: New Prospects for Cytokines brought together researchers and rheumatologists to consider the essential role of cytokines in health and their contributions to autoimmunity. Topics addressed during the Symposium - which was held in Berlin, Germany from 27 to 29 May 2010 - included established and new cytokine targets in arthritis and autoimmunity and innovative aspects of osteoimmunology as well as current perspectives from translational and clinical studies. The keynote lecture, delivered by George Kollias, focused on insights gained from animal models into the mechanisms of TNF function in chronic inflammation and autoimmunity. The presentations at the Symposium resulted in productive discussions regarding potential new targets for the treatment of rheumatoid arthritis and other autoimmune disorders.
\end{abstract}

\section{Introduction}

Following the success of the inaugural Kitasato Symposium in 2009 [1], an international faculty of researchers and rheumatologists met again at the Palais am Festungsgraben, Berlin from the 27 to 29 May 2010 to consider the essential role of cytokines in health and their contributions to autoimmunity. Approximately 50 scientists from around the world attended the meeting to share their experience and expertise in basic research and clinical aspects of cytokines and their targeting in the treatment of autoimmune disorders (see Table 1 for an overview of the main topics).

\section{Keynote lecture}

The keynote lecture was delivered by George Kollias (Athens, Greece) and considered insights gained from animal models on the mechanisms of TNF function in

*Correspondence: thomas.doerner@charite.de

CC12, Charite Universitätsmedizin Berlin, Chariteplatz 01, 10098 Berlin, Germany ${ }^{1}$ Full list of faculy members is available at the end of the article chronic inflammation and autoimmunity. TNF $\alpha$ plays an important physiological role in lymphoid architecture and function [2], but is also involved in the pathology of chronic inflammatory and autoimmune disorders [3]. The pleiotropic effects of TNF reflect the complexity of a system involving both transmembrane and soluble forms of TNF and two receptors mediating different functions (Figure 1), as well as effects that depend on the timing and localisation of TNF production [4].

This complexity raises the important question of whether it may be possible to target the mechanisms by which TNF contributes to disease selectively without suppressing its physiological actions. For example, transgenic mice engineered with an uncleavable TNF protein are protected against bacterial infection, but transmembrane TNF alone is not sufficient to support disease development in the TNF-dependent tristetraprolin knockout model of inflammatory arthritis [5]. Selective blockade of soluble TNF may therefore be a safer alternative to total TNF blockade for the treatment of chronic inflammation and autoimmunity.

Georg Kollias reviewed studies indicating that pathogenic TNF/TNF receptor 1 (TNFR1) signalling in inflammatory diseases of both the joints and intestine may be mediated specifically by mesenchymal cells such as synovial fibroblasts and intestinal myofibroblasts. Selective mesenchymal expression of the TNFR1 allele has been shown to be sufficient for development of a full arthritic and intestinal phenotype in a murine model of spondyloarthritic disease [6]. This may account for the commonly observed synovial-gut axis in human disease and identifies selective targeting of the TNFR1 pathway in mesenchymal cells as a promising therapeutic strategy.

Effects of TNF in supporting the development of follicular dendritic cells (FDCs) and germinal centres may also have important pathological implications. The development of autoantibody-mediated spontaneous arthritis in the $\mathrm{K} / \mathrm{BxN}$ murine model has been shown to be critically dependent on FDCs. FDC-specific expression of TNFR1 was necessary and sufficient to induce clustering of FDCs in B-cell follicles and for germinal centre formation, and FDC depletion resulting from stromal/FDC TNFR1-deficiency led to dramatically 
Table 1. Overview of cytokines and correlated systems addressed at the second Kitasato meeting 2010.

\begin{tabular}{ll}
\hline $\begin{array}{l}\text { Cytokine systems and } \\
\text { cytokine/signalling cascades }\end{array}$ & Specific comments \\
\hline Soluble and membrane-bound TNF & Distinct roles in autoimmunity versus risk of infection \\
& Immunomodulatory effects by TNF blockade on CD4+CD25+ $T_{\text {reg }}$ cells \\
TNFR1 and FDCs & Potential crucial role in autoimmunity \\
STAT1/3 balance & IL-10 resistance can be modulated by TNF and IFN \\
IL-17 & Counter regulation of Th17 versus T reg cells and emerging role of TH17 cells in providing B-cell help \\
IL-33 & Potential role in resistance to intestinal nematode infection; proinflammatory effects in asthma and arthritis \\
IL-35 & Probably immunosuppressive cytokine with potential to expand $T_{\text {reg }}$ cells and suppresses Th17 cells \\
IL-6/IL-6 receptor/glycoprotein 130 & Additional role of this cytokine/signalling system in juvenile arthritis as well as other systemic autoimmune \\
Cytokine/chemokine effects on & disorders. Role of IL-6/IL-6 receptor in glucose metabolism \\
Osteoblast/osteoclast activity & TNFa, IL-1, IL-17A, IL-6, BAFF/BLyS, APRIL, C-C chemokine receptor 2 \\
BAFF/BLyS, APRIL,TNF, IFNa & Role in systemic autoimmunity (that is, systemic lupus erythematosus) \\
GM-CSF receptor blockade & First trial data in human \\
Blockade of IL-17A & First trial data in rheumatoid arthritis patients \\
IL-21 & Role in autoimmunity and potential target of therapy \\
IL-22 & Potential to polarise Th17 cells into immunomodulatory IL-22-producing T cells \\
IL-10 & Additional functions of IL-10-producing B cells for immunomodulation \\
IFNa & Current and new aspects of using IFNa in the treatment of Behçet's disease \\
\hline
\end{tabular}

APRIL, a proliferation-inducing ligand; BAFF, B-cell activating factor belonging to the TNF family; BLyS, B-lymphocyte stimulator; FDC, follicular dendritic cells; GM-CSF, granulocyte/macrophage colony-stimulating factor; STAT, signal transducer and activator of transcription; TNFR1, TNF receptor $1 ; \mathrm{T}_{\text {reg }}$ ' $\mathrm{T}$-regulatory.

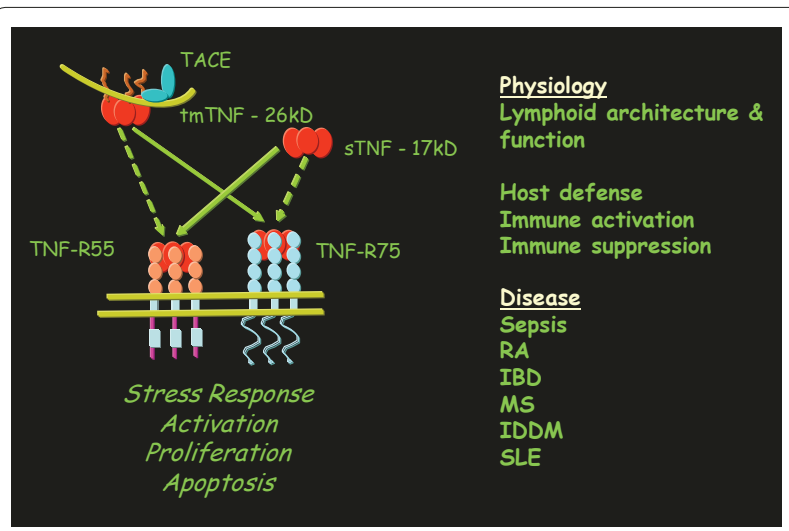

Figure 1. Pleiotropic functions of TNF and TNF receptor. $T A C E$, TNF alpha converting enzyme; tmTNF, transmembrane TNF; TNF, tumour necrosis factor; sTNF, soluble TNF; RA, rheumatoid arthritis; IBD, inflammatory bowel disease; MS, multiple sclerosis; IDDM, insulindependent diabetes mellitus; SLE, systemic lupus erythematosus. Figure kindly provided by Dr George Kollias (Athens, Greece).

reduced production of autoreactive antibodies. Furthermore, anti-TNF treatment with etanercept destabilised FDC networks leading to reductions in germinal centre reactivity, autoantibody production and disease severity [7]. Inhibition of the TNF/TNFR1-mediated activities of FDCs may therefore contribute to the beneficial effects of current anti-TNF therapies as well as being a potential target for novel treatments.

\section{New targets, new mechanism}

Lionel Ivashkiv (New York, USA) considered the regulation of cytokine signalling in inflammatory diseases, focusing on the function of the immunosuppressive and anti-inflammatory cytokine IL-10. The homeostatic effects of IL-10 are mediated via activation of the Janus kinase 1-signal transducer and activator of transcription 3 (STAT3) signalling pathway, but IL-10 also has the IFN $\gamma$-like ability to activate macrophages mediated through STAT1. In rheumatoid arthritis (RA) the balance between activation of STAT3 and STAT1 appears to shift, leading to an attenuation of the anti-inflammatory functions of IL-10 at the same time as its proinflammatory effects are enhanced [8]. TNF may act as an important regulator of the cytokine balance by attenuating STAT3 responses and priming STAT1 responses. This suggests that overcoming IL-10 resistance, increasing IL-10 production, and modulation of IFNs and downstream signalling pathways, possibly in combination with antiTNF treatment, may be potential therapeutic approaches to restoring the cytokine balance in individuals with RA.

Vijay Kuchroo (Harvard, Boston, MA, USA) reviewed recent advances in the understanding of the role of Th17 cells in the induction and regulation of tissue inflammation. Th17 cells have a protective role against certain extracellular pathogens but, when dysregulated, can induce severe inflammation and autoimmunity. They are effective in providing B-cell help: IL-17 specifically 
induces antibody class switching to $\operatorname{IgG}_{2 b}$ and $\operatorname{IgG}_{3}$. Differentiation of Th17 cells in the mouse is induced by transforming growth factor beta together with either IL-6 or IL-21, followed by self-amplification involving IL-21 and then stabilisation by IL-23. Of note, transforming growth factor beta in the absence of IL- 6 and IL-21 promotes the generation of T-regulatory $\left(\mathrm{T}_{\text {reg }}\right)$ cells, resulting in a reciprocal relationship between Th17 and $\mathrm{T}_{\text {reg }}$ cells that may present novel targets for treatment of inflammatory disorders [9].

IL-33 and IL-35 are novel additions to the expanding orchestra of cytokines, and Eddy Y Liew (Glasgow, UK) considered their functions in health and autoimmunity. In mouse models, IL-33 confers resistance to intestinal nematode infection and has cardioprotective activity. IL-33 has been shown, however, to exacerbate asthma, collagen-induced arthritis and Theiler's virus-induced encephalitis, and to induce allergic anaphylaxis, as well as being associated with Alzheimer's disease. In a recent study, IL-33 was shown to attenuate sepsis by preventing the downregulation of CXCR2 expression and chemotaxis, so enhancing neutrophil influx into the infection site [10]. IL-35 is an immunosuppressive cytokine that expands $\mathrm{T}_{\text {reg }}$ cells, suppresses Th17 cell development and enhances Th1 differentiation. Protection against collagen-induced arthritis in mice suggests a possible role for IL-35 in the treatment of inflammatory diseases [11].

Costantino Pitzalis (London, UK) asked whether synovial pathobiology can be used to predict the clinical phenotype and response to treatment in patients with arthritis. RA is a highly heterogeneous condition with a variable clinical course resulting in major differences in joint damage and disability. The Pathobiology of Early Arthritis Cohort is a multicentre collaboration with the aim of identifying and characterising early biomarkers of disease development and progression using minimally invasive, ultrasound-guided synovial biopsy. Information gained will assist with tailoring treatment to achieve optimal outcomes for each patient [12].

\section{Established cytokines and new perspectives}

Norihiro Nishimoto (Osaka, Japan) - one of the pioneers in discovering the role of the IL-6/IL-6 receptor (IL-6R) system - reviewed the results of studies of IL-6 blockade using the humanised anti-IL-6R monoclonal antibody, tocilizumab, in a variety of disorders. Tocilizumab can alleviate many of the manifestations of multicentric Castleman's disease, including chronic inflammatory symptoms, skin rash, wasting, interstitial pneumonia and secondary amyloidosis [13]. Tocilizumab has also been shown to reduce disease activity in both RA [14] and systemic lupus erythematosus (SLE) [15].

IL-6 signals are transmitted via glycoprotein 130, classically as a result of IL-6 binding to the membrane-bound IL-6R. However, IL-6 can also activate glycoprotein 130 through binding to a soluble form of the IL-6R, a phenomenon termed IL-6 trans-signalling. Stefan Rose-John (Kiel, Germany) presented evidence that ADAM17, the disintegrin metalloproteinase responsible for membrane shedding of the IL-6R, may act as a molecular switch between the proinflammatory and antiinflammatory activities of IL- 6 by affecting the balance of signalling between the membrane-bound and soluble forms of the IL-6R. Given that IL- 6 trans-signalling appears to be the predominant mode of IL-6 signalling in inflammatory arthritis [16], Professor Rose-John concluded that selective inhibition of IL-6 trans-signalling (for example, with recombinant variants of soluble glycoprotein 130) may have advantages over global IL-6 blockade.

Jens Brüning (Cologne, Germany) then considered the role of IL-6 in metabolism and obesity-associated insulin resistance. In the acute physiological setting, the actions of IL-6 are antidiabetic, promoting glucose metabolism and muscle glucose uptake in a manner similar to insulin [17]. IL-6 expression in hepatocytes is promoted by neuronal insulin action, and hepatic IL-6 signalling may be important for glucose homeostasis. Knockout mice lacking hepatocyte IL-6Rs exhibit skeletal muscle insulin resistance but hepatic glucose production is unaltered. TNF neutralisation or Kupffer cell ablation can restore glucose sensitivity in the knockout mice, suggesting that IL-6 signalling in hepatocytes may promote glucose disposal by skeletal muscle by limiting Kupffer cell activation and the development of systemic inflammation.

Andrew Cope (London, UK) reviewed the multifaceted immunomodulatory activities of TNF and the effects of TNF blockade. In particular, TNF was found to inhibit the suppressive activity of $\mathrm{CD} 4{ }^{+} \mathrm{CD} 25^{+} \mathrm{T}_{\text {reg }}$ cells, and antiTNF therapy has been shown to restore the deficit of $\mathrm{T}_{\text {reg }}$ suppressive function in patients with RA [18]. Recent studies have also shown that $\mathrm{CD} 4^{+} \mathrm{T}$ cells from patients with RA are defective in the CD3/CD46-induced IFNY/ IL-10 switch in which $T_{\text {reg } 1}$ cells are derived from Th1 precursors, and that this switch is restored by TNF blockade.

\section{Osteoimmunology}

The next session considered the role of cytokines in bone metabolism and arthritis, which has also been recognised by the collaborative research initiative Immunobone from the German Research Council DFG. Recent evidence from animal models indicates that, despite the success of anti-TNF therapy in controlling the signs and symptoms of arthritis, these drugs do not appear to affect the structural changes of ankylosing spondylitis. A new hypothesis for the relationship between inflammation and ankylosis was presented by Rik Lories (Leuven, Belgium), in which the two processes are largely 
molecularly uncoupled but are both triggered by entheseal stress (probably involving biomechanical stress and microdamage; Figure 2) [19]. Lories identified bone morphogenetic protein and Wnt signalling pathways as potential targets for treatment to prevent or delay ankylosis.

Kurt Redlich (Vienna, Austria) discussed chemokine control of bone metabolism based on studies of C-C chemokine receptor 2 knockout mice. CCR2 ${ }^{-/-}$mice have increased bone mass and strength because of a reduction in the number, size and function of osteoclasts, and are protected from osteoporosis [20]. The results indicate a new pathway in the regulation of bone homeostasis in which binding of chemokines to $\mathrm{C}-\mathrm{C}$ chemokine receptor 2 induces signalling via $\mathrm{NFKB}$ and extracellular signalregulated kinase $1 / 2$, leading to increased receptor activator of NFKB (RANK) expression by osteoclast progenitor cells, making them more susceptible to RANK ligand-induced osteoclastogenesis. Cytokine regulation of osteoclastogenesis was considered further by Jochen Zwerina (Erlangen, Germany), with specific reference to TNF, IL-1, IL-17 and IL-6. IL-1 is an essential mediator of TNF-induced osteoclastogenesis while IL-17A blockade has been shown to reduce the production of TNFinduced synovial osteoclasts, although this did not result in improvements in disease severity in the hTNFtg murine model of RA. Recently, IL-6 blockade was shown to potently inhibit osteoclast formation and bone erosion in hTNFtg mice without suppressing joint inflammation, suggesting that IL-6 blockade may have beneficial effects on bone structure in the treatment for arthritis [21].

Michael Cancro (Philadelphia, PA, USA) closed with a presentation on plasma cell-osteoclast cross-talk and the role of the BLyS/BAFF family of ligands and receptors in the development and maintenance of antigen-experienced pools. Bidirectional cross-talk between emerging RANKligand expressing plasma cells and APRIL-producing stromal elements underlies the ability of some antigenexperienced cells, such as long-lived plasma cells, to drive their own niche formation and maintenance. Changes in B-cell sensitivity to and reliance on BLyS/BAFF family ligands contribute to germinal centre competition and selection, through interactions between germinal centre $B$ cells and BLyS/TACI-expressing $\mathrm{T}_{\mathrm{FH}}$ cells [22].

\section{Cytokines and systemic autoimmunity: pros and cons in systemic lupus erythematosus}

Fritz Melchers (Berlin, Germany) began by noting that approximately one-half of all $\mathrm{B}$ cells are located in gutassociated lymphoid tissues, and that very little is known about these cells. Consequently, intestinal bacteria may be important in determining the response to anti-CD20 therapies (for example, rituximab) and, at least in part, account for the variable outcomes seen in clinical

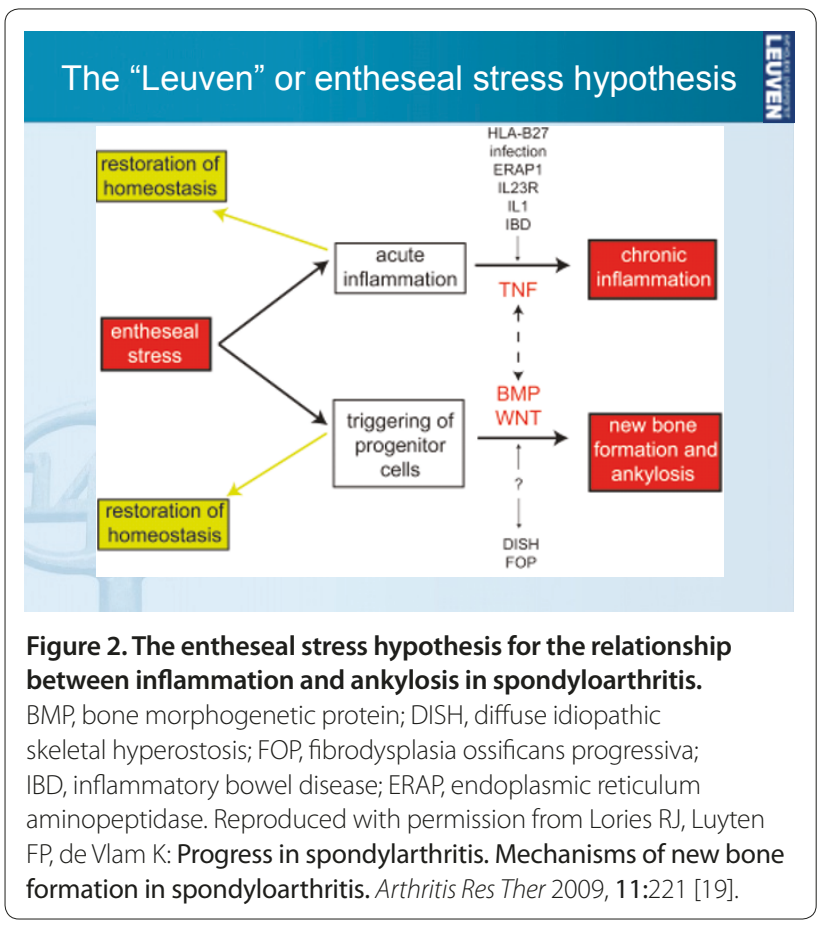

practice. Xavier Mariette (Paris, France) went on to consider the role of cytokines acting on B cells under autoimmune conditions. Early RA is associated with activation of B cells apparently driven by IL- 6 but not BLyS/BAFF. In contrast, BLyS/BAFF does appear to play a role in B-cell activation in Sjögren's syndrome and, in cooperation with IL-17, in SLE [23]. Interestingly, BLyS/ BAFF can be secreted by different types of cells, and in particular epithelial cells, after IFN $\alpha$ stimulation (23bis) and virus infection of these cells. This can explain why BLyS/BAFF is involved in Sjögren's syndrome and in SLE, two diseases associated with an IFN signature (23ter). Exacerbation of IFN $\alpha$ and BLyS/BAFF overexpression may account for the lack of efficacy of TNF blockade (etanercept) as treatment for Sjögren's syndrome [24].

SLE is associated with the production of short-lived plasmablasts with a definite IFN $\alpha$ signature. Recent studies reviewed by Falk Hiepe (Berlin, Germany) have identified a specific plasmablast subset that expresses HLA-DR very strongly, and have shown that this HLA$\mathrm{DR}^{\text {high }}$ cell fraction (but not the HLA-DR ${ }^{\text {low }}$ fraction) correlates closely with SLE disease activity and anti-DNA autoantibody titre [25]. This suggests that plasmablasts may make a distinct contribution to the pathogenesis of SLE, and may also be susceptible to immunosuppressive therapy where more differentiated, long-living plasma cells are resistant.

Martin Schiller (Heidelberg, Germany) considered the evidence that accumulation of apoptotic cell-derived membrane microparticles as a result of increased 
apoptosis or defective phagocytosis may contribute to the autoimmune response in SLE. These microparticles represent a source of nuclear autoantigens and have been shown to induce the maturation of dendritic cells. Further, they stimulated plasmacytoid dendritic cells to produce IFNa.

Martin Aringer (Dresden, Germany) reviewed the role of cytokines other than IFN $\alpha$ in SLE. For example, IFNY signalling via STAT1 is activated in peripheral blood mononuclear cells from patients with SLE [26], and serum levels of TNF and IL-18 have been shown to correlate with SLE disease activity. TNF blockade (infliximab) is associated with clinical improvements in patients with SLE, including a marked reduction in proteinuria, but is also associated with autoantibody production in a majority of patients [27]. TNF blockade was also shown to reduce IL-18 levels, suggesting that TNF to some degree drives IL-18 changes in SLE.

\section{Clinical aspects of cytokine interventions}

Asking whether additional cytokine-targeted therapies are actually needed, Kurt Redlich (Vienna, Austria) identified the goals of therapy in RA as alleviating the signs and symptoms of inflammation, halting and ideally reversing joint destruction, and restoring normal physical function and quality-of-life. Given that treatment should aim for remission, and that this is rarely achieved with current treatment options, Redlich concluded that new biological therapies are indeed needed [28].

Gerd-Rüdiger Burmester (Berlin, Germany) considered the clinical value of blocking signalling via the granulocyte/ macrophage colony-stimulating factor (GM-CSF) pathway. GM-CSF is elevated in synovial fluid from patients with RA, and targeting the GM-CSF pathway in animal models of RA reduced disease activity. Recently, the results from the first study in humans of a monoclonal antibody (CAM-3001) targeting the GM-CSF pathway were reported [29]. CAM-3001 had an acceptable safety profile in the phase I study and presented nonlinear pharmacokinetics, presumably because of an antigensink effect, with a half-life of 11 to 21 days. Although the study was not designed to assess efficacy, improvements in disease activity, reductions in C-reactive protein and normalisation of the erythrocyte sedimentation rate were seen with CAM-3001 and suggest potential clinical benefits of GM-CSF blockade in the treatment of RA.

Hendrik Schulze-Koops (Munich, Germany) presented recent data showing increased IL-17 levels and Th17 cell frequencies in the peripheral circulation of patients with very early psoriatic arthritis or RA, but not osteoarthritis. Inflammatory arthritis is associated with increased expression of Th17 cells that are resistant to the inhibitory effects of IL-4 and IFN $\gamma$, an observation that correlates with disease activity.
Epigenetics describes all heritable and potentially reversible changes in genome function not involving alterations in the DNA nucleotide sequence, and includes mechanisms such as acetylation, ubiquitylation, methylation, phosphorylation and inhibitory RNA (microRNA). Steffen Gay (Zurich, Switzerland) considered the potential role of epigenetic modulation of gene expression in the development of RA. For example, the balance of histone acetyl-transferase/histone deacetylase activity is strongly shifted towards histone hyperacetylation in synovial tissue from patients with RA, and this may lead to the activation of proinflammatory transcription factors [30]. Recent studies have shown that RA is associated with altered microRNA expression, including enhanced expression of microRNA-155, which suppresses levels of matrix metalloproteinase-3, suggesting that microRNAs may be involved in modulating bone destruction by synovial fibroblasts [31]. Research has also shown that the aggressive RA synovial fluid is hypomethylated [32].

\section{Recent translations of cytokine insights from the bench}

Warren Leonard (Bethesda, MD, USA) reviewed the evidence that IL-21 is critical to the development of certain autoimmune diseases, including type I diabetes and SLE, but may also have therapeutic utility for cancer treatment [33]. IL-21 induces the expression of the Prdm1 gene by $\mathrm{B}$ cells and $\mathrm{T}$ cells, which encodes B-lymphocyte-induced maturation protein 1, a critical regulator of plasma cell differentiation. Most IL-21regulated genes, including $\operatorname{Prdm1}$, are associated with combined STAT3- interferon regulatory factor 4 (IRF4) promoter sites, and IL-21-induced STAT3 binding is dramatically reduced in the absence of IRF4 [34]. This suggests an important role for IRF4 alongside STAT3 in the regulation of $\mathrm{T}_{\mathrm{FH}}$ differentiation, which was confirmed. These findings furthermore suggest that other cytokines and biological processes that depend on STAT3 may also utilise IRF4.

IL-22 is a member of the IL-10 family that promotes innate immunity, with overexpression associated with dermatitis and psoriasis. Carlo Chizzolini (Geneva, Switzerland) presented data showing that the production of IL-22 by human Th cells can occur either alongside or independently of IL-17 and/or IFN $\gamma$. The emergence of IL-17-producing and IL-22-producing T cells is differentially regulated, with ligands of the aryl hydrocarbon receptor favouring IL-22 expression and with prostaglandin $E_{2}$ acting synergistically with IL-23 to favour IL-17 expression [35]. The results suggest that signalling through the aryl hydrocarbon receptor may be important in shifting the polarisation of T cells from an IL-17producing phenotype to an IL-22-producing phenotype, with possible clinical consequences in terms of impaired 


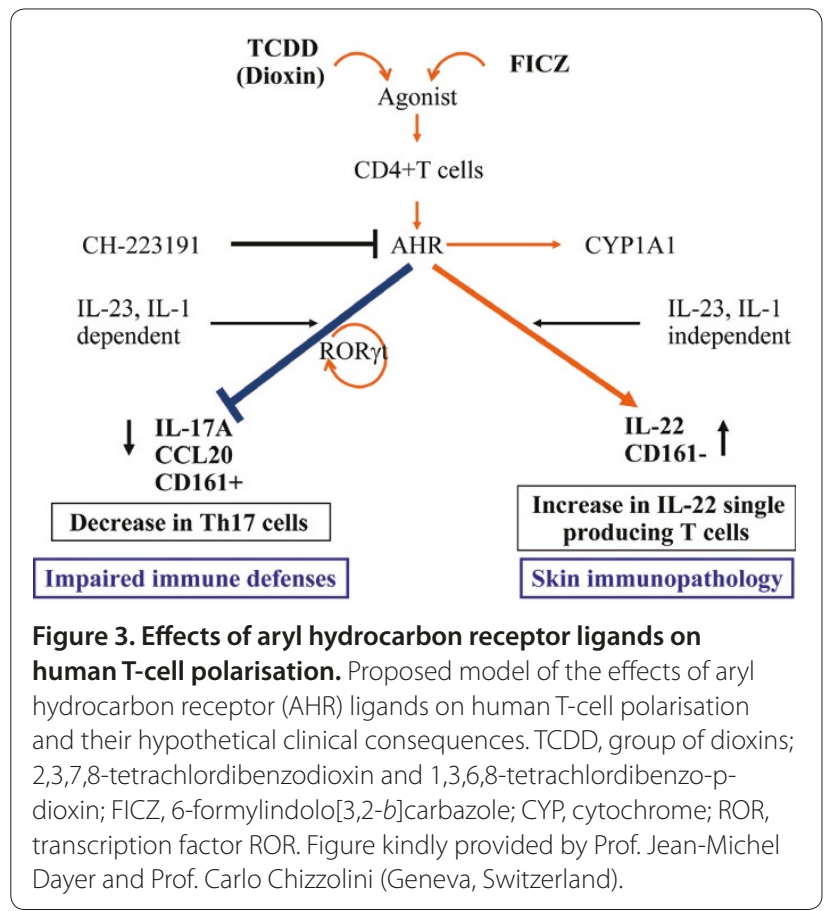

immune defences and skin immunopathology (Figure 3) $[36,37]$.

The potential for B-cell-based therapy in autoimmune disorders was considered by Simon Fillatreau (Berlin, Germany), who asked whether it might be possible to design an ideal therapeutic $B$ cell combining the weak immunogenicity of resting $B$ cells with the effective suppressive functions of activated B cells. Fillatreau reviewed studies showing that quiescent $B$ cells can be reprogrammed to present antigen and secrete IL-10, and that transfer of these reprogrammed B cells protects against experimental autoimmune encephalomyelitis in mice by suppressing adaptive immunity and preventing immune-mediated tissue degradation.

Ina Kötter (Tübingen, Germany) summarised the results of studies investigating IFN $\alpha$ as a treatment for Behçet's disease, which is an inflammatory disorder associated with wide-ranging symptoms including mouth and genital ulcers as well as eye inflammation. A metaanalysis of trials conducted in 2004 indicated that IFNa $\alpha_{2 a}$ is an effective alternative for the treatment of Behçet's disease, particularly with regards to mucocutaneous lesions [38], and subsequent studies have demonstrated consistent benefits [39]. In a recent study, all except one of 53 patients (98\%) with severe uveitis caused by Behçet's disease responded to IFNo $\alpha_{2 a}$ treatment, with treatment discontinued in remission for $89 \%$ of the patients. Fifty per cent of patients were still in remission nearly 4 years after cessation of a first course of IFNa ${ }_{2 a}$ treatment [40]. IFNa ${ }_{2 a}$ was shown to normalise pathologically elevated numbers of $\gamma \delta \mathrm{T}$ cells, as well as decreased intracellular levels of IL2. Serum IFN $\alpha$ levels were already increased in the patients before treatment, however, as were B-cell numbers, and both increased further under therapy. The mechanism of action of IFN $\alpha$ in Behçet's disease hence remains to be clarified, as some of its effects at first sight appear to be more immunostimulatory than immunosuppressive.

\section{Conclusions}

The Second Kitasato Symposium brought together experts in both basic and clinical research to discuss the physiological roles of cytokines as well as their contributions to inflammatory and autoimmune disorders. The lively discussions highlighted the rapid and substantial advances in our understanding of the interplay of inflammatory pathways and elements of the immune system in RA and other disorders. With the insights gained, it may be possible to develop new treatment strategies and interventions with the aim of improving outcomes for the many people affected by autoimmune disorders.

\section{Abbreviations}

ADAM, a disintegrin and metalloproteinase; APRIL, a proliferation-inducing ligand; BAFF, B-cell activating factor belonging to the TNF family; BLyS,

B-lymphocyte stimulator; FDC, follicular dendritic cells; GM-CSF, granulocyte/ macrophage colony-stimulating factor; HLA-DR, human leukocyte antigenDR; hTNFtg, human TNF transgenic; IFN, interferon; IL, interleukin; IL-6R, IL-6 receptor; IRF4, interferon regulatory factor 4 ; $N F$, nuclear factor; RA, rheumatoid arthritis; RANK, receptor activator of NFKB; SLE, systemic lupus erythematosus; STAT, signal transducer and activator of transcription; TACI, transmembrane activator and calcium modulator and cyclophilin ligand interactor; Th, T-helper type; TNF, tumour necrosis factor; TNFR1, TNF receptor $1 ; T_{\text {reg' }}$ T-regulatory; Wnt, wingless-type MMTV integration site family.

\section{Competing interests}

The authors declare that they have no competing interests.

\section{Author details}

'Kitasato Symposium Faculty: M Aringer (Dresden), J Brüning (Cologne), M Cancro (Philadelphia), C Chizzolini (Geneva), A Cope (London), S Fillatreau (Berlin), S Gay (Zurich), F Hiepe (Berlin), L Ivashkiv (New York), G Kollias (Athens), I Kötter (Tübingen), VK Kuchroo (Boston), W Leonard (Bethesda), EY Liew (Glasgow), R Lories (Leuven), X Mariette (Paris), F Melchers (Berlin), N Nishimoto (Osaka), C Pitzalis (London), K Redlich (Vienna), S Rose-John (Kiel), M Schiller (Heidelberg), H Schulze-Koops (Munich), J Zwerina (Erlangen).

Published: 17 December 2010

\section{References}

1. Burmester GR, Lipsky PE, Dörner T, Kitasato Meeting Faculty: Kitasato Symposium 2009: New Prospects for Cytokine Inhibition. Arthritis Res Ther 2009, 11:301.

2. Pasparakis M, Alexopoulou L, Episkopou V, Kollias G: Immune and inflammatory responses in TNF alpha-deficient mice: a critical requirement for TNF alpha in the formation of primary $B$ cell follicles, follicular dendritic cell networks and germinal centers, and in the maturation of the humoral immune response. J Exp Med 1996, 184:1397-1411.

3. Kontoyiannis D, Pasparakis M, Pizarro TT, Cominelli F, Kollias G: Impaired on/ off regulation of TNF biosynthesis in mice lacking TNF AU-rich elements: implications for joint and gut-associated immunopathologies. Immunity 1999, 10:387-398.

4. Apostolaki M, Armaka M, Victoratos P, Kollias G: Cellular mechanisms of TNF 
function in models of inflammation and autoimmunity. Curr Dir Autoimmun 2010, 11:1-26.

5. Alexopoulou L, Kranidioti K, Xanthoulea S, Denis M, Kotanidou A, Douni E, Blackshear PJ, Kontoyiannis DL, Kollias G: Transmembrane TNF protects mutant mice against intracellular bacterial infections, chronic inflammation and autoimmunity. Eur J Immuno/ 2006, 36:2768-2780

6. Armaka M, Apostolaki M, Jacques P, Kontoyiannis DL, Elewaut D, Kollias G: Mesenchymal cell targeting by TNF as a common pathogenic principle in chronic inflammatory joint and intestinal diseases. J Exp Med 2008, 205:331-337.

7. Victoratos P, Kollias G: Induction of autoantibody-mediated spontaneous arthritis critically depends on follicular dendritic cells. Immunity 2009, 30:130-142.

8. Antoniv TT, Ivashkiv LB: Dysregulation of interleukin-10-dependent gene expression in rheumatoid arthritis synovial macrophages. Arthritis Rheum 2006, 54:2711-2721.

9. Awasthi A, Kuchroo VK: Th17 cells: from precursors to players in inflammation and infection. Int Immunol 2009, 21:489-498.

10. Alves-Filho JC, Sônego F, Souto FO, Freitas A, Verri WA Jr, Auxiliadora-Martins M, Basile-Filho A, McKenzie AN, Xu D, Cunha FQ, Liew FY: Interleukin-33 attenuates sepsis by enhancing neutrophil influx to the site of infection. Nat Med 2010, 16:708-712.

11. Niedbala W, Wei XQ, Cai B, Hueber AJ, Leung BP, McInnes IB, Liew FY: IL-35 is a novel cytokine with therapeutic effects against collagen-induced arthritis through the expansion of regulatory T cells and suppression of Th17 cells. Eur JImmunol 2007, 37:3021-3029.

12. Pathobiology of Early Arthritis Cohort [http://www.peac-mrc.mds.qmul. ac.uk/index.php]

13. Nishimoto N, Kanakura Y, Aozasa K, Johkoh T, Nakamura M, Nakano S, Nakano N, Ikeda Y, Sasaki T, Nishioka K, Hara M, Taguchi H, Kimura Y, Kato Y, Asaoku H, Kumagai S, Kodama F, Nakahara H, Hagihara K, Yoshizaki K, Kishimoto T: Humanized anti-interleukin- 6 receptor antibody treatment of multicentric Castleman disease. Blood 2005, 106:2627-2632.

14. Nishimoto N, Hashimoto J, Miyasaka N, Yamamoto K, Kawai S, Takeuchi T, Murata N, van der Heijde D, Kishimoto T: Study of active controlled monotherapy used for rheumatoid arthritis, an IL-6 inhibitor (SAMURAI): evidence of clinical and radiographic benefit from an $\mathrm{X}$ ray reader-blinded randomised controlled trial of tocilizumab. Ann Rheum Dis 2007. 66:1162-1167.

15. Illei GG, Shirota Y, Yarboro CH, Daruwalla J, Tackey E, Takada K, Fleisher T, Balow JE, Lipsky PE: Tocilizumab in systemic lupus erythematosus: data on safety, preliminary efficacy, and impact on circulating plasma cells from an open-label phase I dosage-escalation study. Arthritis Rheum 2010, 62:542-552.

16. Nowell MA, Williams AS, Carty SA, Scheller J, Hayes AJ, Jones GW, Richards PJ, Slinn S, Ernst M, Jenkins BJ, Topley N, Rose-John S, Jones SA: Therapeutic targeting of IL- 6 trans signaling counteracts STAT3 control of experimental inflammatory arthritis. J Immunol 2009, 182:613-622.

17. Carey AL, Steinberg GR, Macaulay SL, Thomas WG, Holmes AG, Ramm G, Prelovsek O, Hohnen-Behrens C, Watt MJ, James DE, Kemp BE, Pedersen BK, Febbraio MA: Interleukin-6 increases insulin-stimulated glucose disposal in humans and glucose uptake and fatty acid oxidation in vitro via AMP-activated protein kinase. Diabetes 2006, 55:2688-2697.

18. Valencia X, Stephens G, Goldbach-Mansky R, Wilson M, Shevach EM, Lipsky PE: TNF downmodulates the function of human $\mathrm{CD} 4{ }^{+} \mathrm{CD} 25^{\text {hi }}$ T-regulatory cells. Blood 2006, 108:253-261.

19. Lories RJ, Luyten FP, de Vlam K: Progress in spondylarthritis. Mechanisms of new bone formation in spondyloarthritis. Arthritis Res Ther 2009, 11:221

20. Binder NB, Niederreiter B, Hoffmann O, Stange R, Pap T, Stulnig TM, Mack M, Erben RG, Smolen JS, Redlich K: Estrogen-dependent and C-C chemokine receptor-2-dependent pathways determine osteoclast behavior in osteoporosis. Nat Med 2009, 15:417-424.

21. Axmann R, Böhm C, Krönke G, Zwerina J, Smolen J, Schett G: Inhibition of interleukin-6 receptor directly blocks osteoclast formation in vitro and in vivo. Arthritis Rheum 2009, 60:2747-2756

22. Treml JF, Hao Y, Stadanlick JE, Cancro MP: The BLyS family: toward a molecular understanding of B cell homeostasis. Cell Biochem Biophys 2009, 53:1-16.

23. Doreau A, Belot A, Bastid J, Riche B, Trescol-Biemont MC, Ranchin B, Fabien N, Cochat P, Pouteil-Noble C, Trolliet P, Durieu I, Tebib J, Kassai B, Ansieau S, Puisieux A, Eliaou JF, Bonnefoy-Bérard N: Interleukin 17 acts in synergy with
B cell-activating factor to influence B cell biology and the pathophysiology of systemic lupus erythematosus. Nat Immunol 2009 10:778-785.

24. Mavragani CP, Niewold TB, Moutsopoulos NM, Pillemer SR, Wahl SM, Crow MK: Augmented interferon-alpha pathway activation in patients with Sjögren's syndrome treated with etanercept. Arthritis Rheum 2007, 56:3995-4004.

25. Jacobi AM, Mei H, Hoyer BF, Mumtaz IM, Thiele K, Radbruch A, Burmester GR, Hiepe F, Dörner T: HLA-DR ${ }^{\text {high} / C D 27 ~} 7^{\text {high }}$ plasmablasts indicate active disease in patients with systemic lupus erythematosus. Ann Rheum Dis 2010, 69:305-308.

26. Karonitsch T, Feierl E, Steiner CW, Dalwigk K, Korb A, Binder N, Rapp A, Steine G, Scheinecker C, Smolen J, Aringer M: Activation of the interferon-gamma signaling pathway in systemic lupus erythematosus peripheral blood mononuclear cells. Arthritis Rheum 2009, 60:1463-1471.

27. Aringer M, Steiner G, Graninger WB, Höfler E, Steiner CW, Smolen JS: Effects of short-term infliximab therapy on autoantibodies in systemic lupus erythematosus. Arthritis Rheum 2007, 56:274-279.

28. Smolen JS, Aletaha D, Koeller M, Weisman MH, Emery P. New therapies for treatment of rheumatoid arthritis. Lancet 2007, 370:1861-1874.

29. Burmester GR, Wagner F, Feist E, Sleeman M, Magrini F, White B: CAM-3001; a novel human monoclonal antibody against GM-CSFR-a, in subjects with rheumatoid arthritis (RA): results of a Phl study [abstract 1926]. Arthritis Rheum 2009, 60(Suppl 2):1926.

30. Huber LC, Brock M, Hemmatazad H, Giger OT, Moritz F, Trenkmann M, Distler JH, Gay RE, Kolling C, Moch H, Michel BA, Gay S, Distler O, Jüngel A: Histone deacetylase/acetylase activity in total synovial tissue derived from rheumatoid arthritis and osteoarthritis patients. Arthritis Rheum 2007, 56:1087-1093.

31. Stanczyk J, Pedrioli DM, Brentano F, Sanchez-Pernaute O, Kolling C, Gay RE, Detmar M, Gay S, Kyburz D: Altered expression of MicroRNA in synovial fibroblasts and synovial tissue in rheumatoid arthritis. Arthritis Rheum 2008, 58:1001-1009.

32. Karouzakis E, Gay RE, Michel BA, Gay S, Neidhart M: DNA hypomethylation in rheumatoid arthritis synovial fibroblasts. Arthritis Rheum 2009, 60:3613-3622

33. Spolski R, Leonard WJ: Interleukin-21: basic biology and implications for cancer and autoimmunity. Annu Rev /mmunol 2008, 26:57-79.

34. Kwon H, Thierry-Mieg D, Thierry-Mieg J, Kim HP, Oh J, Tunyaplin C, Carotta S, Donovan CE, Goldman ML, Tailor P, Ozato K, Levy DE, Nutt SL, Calame K, Leonard WJ: Analysis of interleukin-21-induced Prdm1 gene regulation reveals functional cooperation of STAT3 and IRF4 transcription factors. Immunity 2009, 31:941-952.

35. Ramirez JM, Brembilla NC, Sorg O, Chicheportiche R, Matthes T, Dayer JM, Saurat JM, Roosnek E, Chizzolini C: Activation of the aryl hydrocarbon receptor in vivo primes human $T$ cells for interleukin 22 production and inhibits Th17 cells. Ann Rheum Dis 2010, 69:A7. doi:10.1136/ard.2010.129668y.

36. Ramirez JM, Brembilla NC, Sorg O, Chicheportiche R, Matthes T, Dayer JM, Saurat JH, Roosnek E, Chizzolini C: Activation of the aryl hydrocarbon receptor reveals distinct requirements for IL-22 and IL-17 production by human Thelper cells. Eur J Immunol 2010, 40:2450-2459.

37. Chizzolini C, Chicheportiche R, Alvarez M, de Rham C, Roux-Lombard P, Ferrari-Lacraz S, Dayer JM: Prostaglandin $\mathrm{E}_{2}\left(\mathrm{PGE}_{2}\right)$ synergistically with interleukin-23 (IL-23) favors human Th17 expansion. Blood 2008, 112:3696-3703.

38. Kötter I, Gunaydin I, Zierhut M, Stubiger N: The use of interferon a in Behçet disease: review of the literature. Semin Arthritis Rheum 2004, 33:320-335.

39. Guillaume-Czitrom S, Berger C, Pajot C, Bodaghi B, Wechsler B, Kone-Paut I: Efficacy and safety of interferon-alpha in the treatment of corticodependent uveitis of paediatric Behcet's disease. Rheumatology 2007, 46:1570-1573.

40. Deuter CM, Zierhut M, Möhle A, Vonthein R, Stübiger N, Kötter I: Long-term remissions after cessation of interferon alpha treatment in patients with severe uveitis due to Behçet's disease. Arthritis Rheum 2010, 62:2796-2805.

doi:10.1186/ar3196

Cite this article as: Burmester GR, et al.: Kitasato Symposium 2010:

New Prospects for Cytokines. Arthritis Research \& Therapy 2010, 12:301. 